\title{
Surgical Crown Lengthening: Evaluation of the Biological Width
}

\author{
Sharon K. Lanning, ${ }^{*}$ Thomas C. Waldrop, ${ }^{\dagger}$ John C. Gunsolley, ${ }^{\ddagger}$ and J. Gary Maynard§
}

Background: Previous surgical crown lengthening studies have investigated positional changes of the free gingival margin but not the biological width. Histological studies utilizing animal models have shown that postoperative crestal resorption allowed reestablishment of the biological width. However, very little work has been done in humans. Therefore, the purpose of this study was to evaluate the positional changes of the periodontal tissues, particularly the biological width, following surgical crown lengthening in human subjects.

Methods: Twenty-three (23) patients who needed surgical crown lengthening to gain retention necessary for prosthetic treatment and/or to access caries, tooth fracture, or previous prosthetic margins entered the study. The following parameters were obtained from line angles of treated teeth (teeth requiring surgical crown lengthening) and adjacent teeth with adjacent and non-adjacent sites: plaque and gingival indexes, free gingival margin, probing depth, attachment level, bone level, direct bone level, and biological width. During surgery, the bone level was reduced based on the future prosthetic margin and predetermined biological width; flaps were placed at the bony crest. Patients were examined at baseline and at 3 and 6 months postoperatively.

Results: Eighteen patients completed the study. Overall, the amount of bone resected was 1 to $5 \mathrm{~mm}$. At $90 \%$ of treated sites, $\geq 3 \mathrm{~mm}$ of bone was removed. At 3 months, the apical displacement of the free gingival margin at non-adjacent, adjacent, and treated sites was $2.46 \pm 0.25 \mathrm{~mm}, 2.68 \pm 0.20 \mathrm{~mm}$, and $3.07 \pm$ $0.16 \mathrm{~mm}$, respectively. There was no significant change in the position of the free gingival margin from 3 to 6 months. The biological width at all sites was smaller at 3 and 6 months compared to baseline $(P<0.05)$ except for the treated sites, which were not significantly different from baseline at 6 months.

Conclusions: During surgical crown lengthening, the bone level was lowered for placement of the prosthetic margin and reestablishment of the biological width. The biological width, at treated sites, was reestablished to its original vertical dimension by 6 months. In addition, a consistent $3 \mathrm{~mm}$ gain of coronal tooth structure was observed at the 3- and 6-month examinations. J Periodontol 2003; 74:468-474.

\section{KEY WORDS}

Biologic width; crown lengthening, surgical; periodontium/ anatomy and physiology; surgical flaps.

\footnotetext{
* Currently, Department of Periodontics/Prevention/Geriatrics, University of Michigan, School of Dentistry, Ann Arbor, MI; previously, Department of Periodontics, Virginia Commonwealth University, School of Dentistry, Richmond, VA.

$\dagger$ Department of Periodontics, Virginia Commonwealth University.

† Department of Periodontics, University of Maryland, School of Dentistry, Baltimore, MD.

$\S$ Private practice, Richmond, VA.
}

$\mathrm{T}$ The preservation of a healthy periodontium is critical for the long-term success of a restored tooth. Dentists must constantly balance the restorative and esthetic needs of their patients with periodontal health. Supragingival placement of restorative margins allows for ease of impression making, cleansing, ${ }^{1}$ detection of secondary caries, and is associated with maintainable probing depths $s^{1,2}$ and healthy soft tissue. ${ }^{2-7}$ However, in cases of extensive caries, tooth fracture, dentinal hypersensitivity, inadequate crown length, and increased esthetic demands, restorative margins need to be placed at or apical to the gingival margin. Subgingival restorations can have damaging effects on the neighboring hard and soft tissues, especially when they encroach on the junctional epithelium and supracrestal connective tissue. ${ }^{4}$ These subgingivally placed restorations have been associated with gingival inflammation, ${ }^{2-7}$ loss of connective tissue attachment, and bone resorption. ${ }^{8-10}$

Crown lengthening involves the surgical removal of hard and soft periodontal tissues to gain supracrestal tooth length, allowing for longer clinical crowns ${ }^{11-14}$ and reestablishment of the biological width. ${ }^{15-17}$ The concept of the biological width stems from a histologic description of the dentogingival complex by Gargiulo et al. ${ }^{18}$ Considerable variation in the magnitude or length of this complex was reported; however, the mean sulcus depth was $0.69 \mathrm{~mm}$, epithelial attachment was $0.97 \mathrm{~mm}$, and connective tissue was $1.07 \mathrm{~mm}$. Therefore, the total length of the dentogingival complex was $2.73 \mathrm{~mm}$. Based on these dimensions, 
several authors $10,19,20$ suggested that $3 \mathrm{~mm}$ of supracrestal tooth structure be obtained during surgical crown lengthening. However, Rosenberg et al. ${ }^{14}$ combined epithelial and connective tissue attachment of $2 \mathrm{~mm}$ with 1 to $2 \mathrm{~mm}$ for the restorative finish line, resulting in a recommendation of 3.5 to $4.0 \mathrm{~mm}$. In addition, Wagenberg et al. ${ }^{21}$ suggested that at least 5.00 to $5.25 \mathrm{~mm}$ of tooth structure should be above the osseous crest. However, setting fixed measurements on the biological width disregards its variability from tooth to tooth and from surface to surface around the same tooth. ${ }^{9,19,22}$

Previously reported clinical studies on surgical crown lengthening have followed positional changes of the free gingival margin immediately after surgery and during healing but have not focused on the biological width. ${ }^{15,23,24}$ A few histological studies utilizing animal models have shown postoperative crestal resorption after denudation, ${ }^{16}$ and scaling and root planing ${ }^{17}$ allowed the reestablishment of connective tissue attachment. However, very little work has been done to confirm these results in human clinical trials. Therefore, the purpose of this study was to evaluate the positional changes of the periodontal tissues, particularly the biological width, following surgical crown lengthening in human subjects over a 6 -month healing period.

\section{MATERIALS AND METHODS}

The university committee governing the use of human subjects in clinical studies approved the study protocol. Patients received a description of the study and provided written informed consent. Twenty-three periodontally healthy patients aged 28 to 72 (mean age 39 years) required surgical crown lengthening to 1) gain retention in sites with insufficient supracrestal tooth structure necessary for prosthetic treatment, and/or 2) access caries, tooth fracture, or previous prosthetic margins. Review of medical and dental histories and intraoral examination demonstrated no systemic or local contraindications to surgical treatment. Prior to surgery, patients had their teeth professionally cleaned and received oral hygiene instructions.

A full-arch acrylic stent was fabricated for each patient, and vertical grooves were created at appropriate interproximal sites to standardize probe placement and angulation. All measurements were obtained with a standardized UNC-15" periodontal probe and rounded up to the nearest millimeter. The following

Figure $I$.

Table I.

Prior to
Surgery

PD
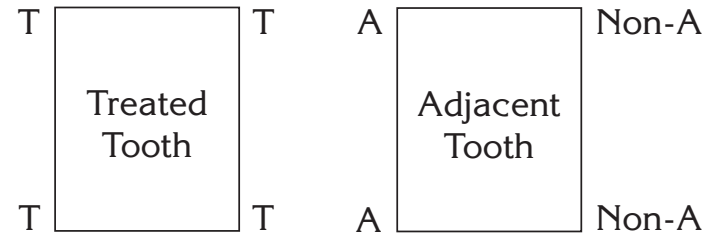

Experimental teeth. Treated tooth with treated sites $(T)$, adjacent teeth with adjacent

Sequence of Measurements and Calculations After Flap

Prior to Reflection

3-Month

6-Month

Surgery and Surgery

Examination

Examination

probing depth (PD), bone level (BL), biological width (BioW), and direct bone level (DBL).

DBL

$\mathrm{DBL}$

FGM

FGM

$\mathrm{AL}$

$\mathrm{AL}$

PD

PD

$B L$

$B L$

BioW

BioW $\mathrm{PD}$ and BioW are calculated measurements.

clinical parameters were obtained at 4 sites (mesiobuccal, mesio-lingual, disto-buccal, disto-lingual) around each tooth requiring crown lengthening (treated sites) and on the adjacent tooth or teeth with adjacent and non-adjacent sites (Fig. 1):

- Plaque index (PI) according to Silness and Löe. ${ }^{25}$

- Gingival index (GI) according to Löe and Silness. ${ }^{26}$

- The reference stent to the free gingival margin.

- The reference stent to the base of the pocket described as the attachment level.

- The probing depth was calculated by subtracting the measurements of the free gingival margin from the attachment level.

- After the experimental area was anesthetized, the bone level was obtained via transgingival probing from the reference stent.

- The biological width was calculated by subtracting the measurements of bone level from attachment level.

- The direct bone level was measured from the reference stent to the bone level after flap reflection.

|| Hu-Friedy, Chicago, IL. 
The exact sequence of measurements and calculations is shown in Table 1. All measurements were taken by one examiner (SKL).

Immediately prior to surgery, all measurements were determined in the sequence outlined above. The magnitude of the biological width was added to the amount of supracrestal tooth structure needed for placement of the prosthetic margin. ${ }^{22}$ The level of the osseous crest was lowered based on this amount using a combination of rotary and hand instruments. The original bone width was maintained at all sites after ostectomy. For adjacent teeth, osseous resection was in keeping with positive architecture. ${ }^{27}$ Osseous resection was performed by one examiner (SKL).

An inverse beveled incision and full-thickness mucogingival flap reflection were performed. Osseous resection was performed as described above. The soft tissue flaps were positioned at the bony crest and sutured. Patients were prescribed a non-steroidal anti-inflammatory analgesic and instructed to rinse with $0.12 \%$ chlorhexidine gluconate twice daily for 2 weeks. Sutures were removed 10 to 14 days after surgery. At this time, patients had their teeth professionally cleaned, then continued with their maintenance program every 3 months. Prosthetic treatment resumed no earlier than 6 weeks after surgery. Patients were anesthetized at the 3- and 6-month examination, and measurements were obtained and calculated as presented in Table 1.

\section{Statistical Analysis}

Means were obtained for each type of site by patient to evaluate differences in non-adjacent, adjacent, and treated sites from baseline to 3 and 6 months. Using these means as the response variables, repeated measures analysis of variance (ANOVA) was used to determine whether there was an overall effect. Tukey's test for multiple comparisons was used to determine which sites had greater changes.

\section{RESULTS}

Eighteen patients completed this study, and no complications related to the surgery or prosthetic treatment were observed. Ninety-eight percent of treated teeth were restored with a fixed prosthesis by the study's end.

\section{Plaque and Gingival Indexes}

During this study, there were no significant changes in PI or GI at non-adjacent, adjacent, or treated sites. The mean PI and GI ranged between 0.41 to 0.62 and 0.34 to 0.73 , respectively.

\section{Free Gingival Margin}

The mean distances from the reference stent to the free gingival margin at baseline and at 3 and 6 months for non-adjacent, adjacent, and treated sites are presented in Table 2. At all sites, there was a difference in the apical displacement of the free gingival margin from baseline to 3 and 6 months $(P<0.0001)$ (Table 3$)$. At 3 months, this displacement at non-adjacent, adjacent, and treated sites was $2.46 \pm 0.25 \mathrm{~mm}, 2.68 \pm$ $0.20 \mathrm{~mm}$, and $3.07 \pm 0.16 \mathrm{~mm}$, respectively. At 6 months, the displacement of the free gingival margin for non-adjacent, adjacent, and treated sites was $2.78 \pm 0.28 \mathrm{~mm}, 2.82 \pm 0.24 \mathrm{~mm}$, and $3.33 \pm 0.15 \mathrm{~mm}$, respectively. There was no significant change in the position of the free gingival margin from 3 to 6 months. The location of the free gingival margin for treated sites was, on average, $0.61 \mathrm{~mm}$ more apical compared to non-adjacent sites at 3 months $(P<0.05)$ (Table 3$)$. At 6 months, the free gingival margin for treated sites was, on average, $0.55 \mathrm{~mm}$ and $0.51 \mathrm{~mm}$ more apical compared to non-adjacent and adjacent sites, respectively $(P<0.05)$ (Table 3).

Il Peridex, Procter $\&$ Gamble, Cincinnati, $\mathrm{OH}$. 
Table 3.

Mean Changes in Clinical Parameters from Baseline to 3- and 6-Month Examinations for Treated, Adjacent, and Non-Adjacent Sites

\begin{tabular}{lllllll}
\hline Examination & \multicolumn{1}{c}{ Sites } & FGM & AL & PD & BL \\
\hline 3-Month & Non-Adjacent & $2.46 \pm 0.25$ & $2.88 \pm 1.98$ & $0.31^{\ddagger} \pm 0.39$ & $2.45 \pm 0.86$ & $-0.42^{\S} \pm 0.07$ \\
& Adjacent & $2.68 \pm 0.20$ & $3.07 \pm 0.96$ & $0.24^{\ddagger} \pm 0.55$ & $2.53 \pm 0.78$ & $-0.29 \S \pm 0.09$ \\
& Treated & $3.07^{\dagger} \pm 0.16$ & $3.75^{*} \pm 0.85$ & $0.67^{* \ddagger} \pm 0.51$ & $3.44^{*} \pm 0.58$ & $-0.3 l^{\S} \pm 0.12$ \\
& Non-Adjacent & $2.78 \pm 0.28$ & $2.71 \pm 0.96$ & $-0.03^{\ddagger} \pm 0.35$ & $2.47 \pm 0.88$ & $-0.23^{\S} \pm 0.06$ \\
6-Month & Adjacent & $2.82 \pm 0.24$ & $2.92 \pm 0.92$ & $-0.04^{\ddagger} \pm 0.52$ & $2.54 \pm 0.76$ & $-0.15^{\S} \pm 0.07$ \\
& Treated & $3.33^{*} \pm 0.15$ & $3.57 * \pm 0.70$ & $0.22^{\ddagger} \pm 0.50$ & $3.50^{*} \pm 0.59$ & $-0.07 \pm \pm 0.09$ \\
\hline
\end{tabular}

Mean changes in the free gingival margin (FGM), attachment level (AL), probing depth (PD), bone level (BL), and biological width (BioW) from baseline to 3 and 6 months postoperatively. Mean values in millimeters \pm standard error.

Unless indicated, all changes over time were statistically different from baseline $(P<0.0001)$

* $P<0.05$ from all other sites.

$\dagger P<0.05$ from non-adjacent sites.

‡ Not different from baseline.

$\S P<0.05$ from baseline.

\section{Attachment Level}

The mean distances from the reference stent to the base of the sulcus at baseline and at 3 and 6 months for non-adjacent, adjacent, and treated sites are presented in Table 2. From baseline to 3 and 6 months, there was an apical shift in the base of the sulcus at all sites $(P<0.0001)$ (Table 3$)$. At 3 months, the loss of attachment for non-adjacent, adjacent, and treated sites was $2.88 \pm 1.98 \mathrm{~mm}, 3.07 \pm 0.96 \mathrm{~mm}$, and $3.75 \pm$ $0.85 \mathrm{~mm}$, respectively. At 6 months, the loss of attachment for non-adjacent, adjacent, and treated sites was $2.71 \pm 0.96 \mathrm{~mm}, 2.92 \pm 0.92 \mathrm{~mm}$, and $3.57 \pm 0.70$ $\mathrm{mm}$, respectively. There was no significant change in attachment level at all sites from 3 to 6 months. The attachment loss for treated sites compared to nonadjacent and adjacent sites was greater at 3 and 6 months $(P<0.05)$ (Table 3$)$.

\section{Probing Depth}

The mean probing depths at baseline and at 3 and 6 months for non-adjacent, adjacent, and treated sites are presented in Table 2. At all sites, the probing depths from baseline to 3 months increased and then decreased by 6 months; these changes did not reach significance. There was no significant difference in mean probing depths at any site between baseline, 3, and 6 months (Table 3). At 3 months, the mean probing depth for treated

Table 4. sites was $3.17 \pm 0.74 \mathrm{~mm}$ (Table 2); this was greater compared to non-adjacent and adjacent sites $(P<0.05)$ (Table 3).

\section{Bone Level}

The mean distances from the reference stent to the bone level at baseline and prior to flap reflection for non-adjacent, adjacent, and treated sites were $9.49 \pm$ $1.33 \mathrm{~mm}, 9.58 \pm 1.37 \mathrm{~mm}$, and $9.33 \pm 1.72 \mathrm{~mm}$, respectively (Table 2 ). There was no difference between bone level measurements taken before and after flap reflection (Table 4). The distribution of bone removed during surgical crown lengthening is presented in Table 5. Overall, the amount of bone resected ranged from 1 to $5 \mathrm{~mm}$. At $21 \%$ of non-adjacent sites, 39\% of adjacent sites, and $90 \%$ of treated sites, $\geq 3 \mathrm{~mm}$ of bone was removed. The change in direct bone level before and after osseous resection at non-adjacent,

\section{Bone Level and Direct Bone Level Measurements at Treated, Adjacent, and Non-Adjacent Sites}

\begin{tabular}{|c|c|c|c|c|}
\hline Sites & $\begin{array}{c}\mathrm{BL} \\
\text { Baseline }\end{array}$ & $\begin{array}{c}\mathrm{DBL} \\
\text { Immediately Before } \\
\text { Osseous Resection }\end{array}$ & $\begin{array}{c}\text { DBL } \\
\text { Immediately After } \\
\text { Osseous Resection }\end{array}$ & $\begin{array}{c}\text { BL } \\
3 \text { Months }\end{array}$ \\
\hline Non-Adjacent & $9.49 \pm 1.33$ & $9.49 \pm 1.30$ & $|1.07 \pm 1.7|$ & $11.94 \pm 1.74$ \\
\hline Adjacent & $9.58 \pm 1.37$ & $9.58 \pm 1.33$ & $11.42 \pm 1.56$ & $12.11 \pm 1.74$ \\
\hline Treated & $9.33 \pm 1.72$ & $9.33 \pm 1.74$ & $12.01 \pm 1.87$ & $12.78 \pm 1.82$ \\
\hline
\end{tabular}

Mean distances from reference stent to bone level (BL) at baseline, direct bone level (DBL) immediately before and after osseous resection, and $\mathrm{BL}$ at the 3 -month examination. Mean values in millimeters \pm standard error. 
Table 5.

Distribution of Bone Removed at Treated, Adjacent, and Non-Adjacent Sites

\begin{tabular}{ccccccc}
\hline \multirow{2}{*}{$\begin{array}{c}\text { Bone Removed } \\
(\mathrm{mm})\end{array}$} & \multicolumn{2}{c}{ Non-Adjacent } & \multicolumn{2}{c}{ Adjacent } & \multicolumn{2}{c}{ Treated } \\
\cline { 2 - 7 } & $\mathrm{N}(62)$ & $\%$ & $\mathrm{~N}(62)$ & $\%$ & $\mathrm{~N}(72)$ & $\%$ \\
\hline 0 & 12 & 19 & 0 & - & 0 & - \\
1 & 15 & 24 & 17 & 27 & 0 & - \\
2 & 22 & 36 & 21 & 34 & 7 & 10 \\
3 & 13 & 21 & 23 & 37 & 45 & 63 \\
4 & 0 & - & 1 & 2 & 19 & 26 \\
5 & 0 & - & 0 & - & 1 & 1 \\
\hline
\end{tabular}

adjacent, and treated sites was $1.58 \mathrm{~mm}, 1.84 \mathrm{~mm}$, and $2.68 \mathrm{~mm}$, respectively (Table 4 ). The mean difference in the direct bone level immediately after osseous resection and bone level at the 3-month examination for non-adjacent, adjacent, and treated sites was $0.87 \mathrm{~mm}$, $0.69 \mathrm{~mm}$, and $0.77 \mathrm{~mm}$, respectively (Table 4).

The mean distances from the reference stent to the bone level at baseline and at 3 and 6 months for nonadjacent, adjacent, and treated sites are presented in Table 3. At all sites, the apical shift in bone level was different from baseline to 3 and 6 months $(P<0.0001)$. At non-adjacent, adjacent, and treated sites, the change in bone level at 3 months was $2.45 \pm 0.86 \mathrm{~mm}$, $2.53 \pm 0.78 \mathrm{~mm}$, and $3.44 \pm 0.58 \mathrm{~mm}$, respectively (Table 3). At non-adjacent, adjacent, and treated sites, the change in bone level at 6 months was $2.47 \pm$ $0.88 \mathrm{~mm}, 2.54 \pm 0.76 \mathrm{~mm}$, and $3.50 \pm 0.59 \mathrm{~mm}$, respectively. There was no change in the bone level at any site from 3 to 6 months. At 3 and 6 months, the bone level at treated sites was at a more apical position compared to non-adjacent and adjacent sites ( $P$ $<0.05$ ) (Table 3).

\section{Biological Width}

The mean vertical dimension of the biological widths at baseline and at 3 and 6 months for non-adjacent, adjacent, and treated sites is presented in Table 3. The biological width at all sites was smaller at 3 and 6 months compared to baseline $(P<0.05)$ except for treated sites, which were not significantly different from baseline at 6 months (Table 3). At non-adjacent, adjacent, and treated sites, the change in biological width at 3 months was $0.42 \pm 0.07 \mathrm{~mm}, 0.29 \pm 0.09 \mathrm{~mm}$, and $0.31 \pm 0.12 \mathrm{~mm}$, respectively (Table 3 ). At nonadjacent, adjacent, and treated sites, the change in biological width at 6 months was $-0.23 \pm 0.06 \mathrm{~mm}$, $-0.15 \pm 0.07 \mathrm{~mm}$, and $-0.07 \pm 0.09 \mathrm{~mm}$, respectively.

\section{DISCUSSION}

This human clinical investigation demonstrated a $3 \mathrm{~mm}$ gain of coronal tooth structure after ostectomy and apically positioned flap surgery, and stability of the free gingival margin between 3 and 6 months. At treated sites, there was no difference in the mean apical displacement of the free gingival margin at 3 and 6 months. There was a significant difference in the apical position of the free gingival margin at treated sites compared to non-adjacent sites at 3 months and adjacent and non-adjacent sites at 6 months. This could be attributed to the surgical technique. The amount of bone resected at treated sites was based on the location of the intended prosthetic margin and the original length of the biological width. ${ }^{22}$ Overall, the amount of bone resected ranged between 1 to $5 \mathrm{~mm}$; and at $90 \%$ of treated sites, $39 \%$ of adjacent sites, and $22 \%$ of nonadjacent sites, $\geq 3 \mathrm{~mm}$ of bone was removed. The magnitude of bone resected in this study is greater than in previous reports and may have contributed to the stability of the free gingival margin. Bragger et al. ${ }^{23}$ reported a 1 to $3 \mathrm{~mm}$ coronal shift of the free gingival margin at 33\% of sites between 6 weeks and 6 months following surgical crown lengthening, and bone resection of $\geq 3 \mathrm{~mm}$ at only $4 \%$ of sites. Pontoriero and Carnevale ${ }^{24}$ also observed a coronal shift in the free gingival margin of $3.2 \mathrm{~mm}$ at interproximal sites and $2.9 \mathrm{~mm}$ at buccal/lingual sites between 1 and 12 months. The mean amount of osseous resection was $0.9 \mathrm{~mm}$ for interproximal sites and $1.0 \mathrm{~mm}$ for buccal/lingual sites. Bone resection was $\geq 2 \mathrm{~mm}$ in only $8 \%$ of sites. Lindhe and Nyman ${ }^{28,29}$ assessed the position of the free gingival margin in periodontal patients undergoing surgical elimination of pockets deeper than $4 \mathrm{~mm}$ where bone contouring was indicated due to the presence of vertical osseous defects and crater formation. Two months after surgical treatment, the free gingival margin was apically displaced by $2.5 \mathrm{~mm}$. Furthermore, the position of the free gingival margin remained relatively stable throughout the 10 to 11 years of maintenance, advancing coronally by only 0.6 to $1.1 \mathrm{~mm}$.

At the majority of sites in our study, the biological width after surgical crown lengthening was significantly smaller compared to baseline. The change in biological width ranged between 0.07 and $0.42 \mathrm{~mm}$. These findings are consistent with previous studies. Oakley et al. ${ }^{17}$ reported that the mean reduction in supracrestal tissue (defined as the distance from the bone level to the free gingival margin) was $0.7 \mathrm{~mm}$ in maxillary sites and $0.1 \mathrm{~mm}$ in mandibular sites compared to controls 12 weeks after surgery. Caton and Nyman ${ }^{30}$ reported a reduced distance from the free gingival margin to the apical extent of the junctional epithelium 12 months following osseous surgery. 
A notable trend in our study was that the biological width at all sites from 3 to 6 months increased (i.e., approached baseline measurements). This is attributed to a slight gain in attachment level and apical displacement of the bone level. Oakley et al. ${ }^{17}$ and Carnevale et al. ${ }^{16}$ reported that bone resorption following surgical crown lengthening provides supracrestal tooth structure for the attachment of connective tissue, leading to reestablishment of the biological width. At treated sites, the biological width at 3 months was significantly different compared to baseline; however, at 6 months, there was no significant difference compared to baseline. In other words, the original vertical dimension of the biological width was reestablished at treated sites 6 months following surgical crown lengthening. This may be due to the surgical technique since greater amounts of bone were resected at treated sites compared to adjacent and non-adjacent sites, creating more supracrestal tooth structure.

An anticipated loss of attachment and bone height was recorded 3 months following surgical crown lengthening. The changes in bone level immediately after osseous surgery and at the 3-month examination are consistent with changes seen in functional repair of bone. Pennel et al. ${ }^{31}$ and Donnenfeld et al. ${ }^{32}$ reported a mean reduction of 0.5 and $1.0 \mathrm{~mm}$ in crestal bone height following osseous surgery and a 6 -month healing period, respectively. Wilderman et al. ${ }^{33}$ observed an average reduction in bone height of $0.8 \mathrm{~mm}$ following bone repair after osseous resective surgery in 23 human subjects. The authors reported that osteoblastic activity reached its peak between the third and fourth week following osseous resective surgery. In addition, soft tissue repair including the reestablishment of attached epithelium and connective tissue began at 1 week postoperatively and reached functional maturity between 6 and 9 months after surgery. In our present study, attachment levels and bone levels remained stable between the 3- and 6-month examination.

The probing depths at all sites after surgery were not significantly different from baseline, and this is consistent with other reports on surgical crown lengthening. ${ }^{25,26}$ The probing depth at the 3-month examination for treated sites was significantly greater than adjacent and non-adjacent sites, measuring approximately $3 \mathrm{~mm}$. At the 3 -month examination, most treated teeth were still undergoing prosthetic treatment. Manipulation of adjacent soft tissue and provisional restorations could have led to this observation. ${ }^{34,35}$ Throughout this study, there were no significant changes in PI or GI at any site.

The literature is inconsistent as to the advantage of manual versus controlled-force probes in terms of improving intraexaminer reproducibility ${ }^{36-38}$ and repeata- bility of linear measurements. ${ }^{36,37}$ In our study, a manual probe offered greater practicality in obtaining measurements, particularly bone level via transgingival probing, and therefore was the chosen method for obtaining all clinical parameters over time. In addition, measurements were obtained by only one examiner (SKL) with a standardized periodontal probe utilizing reference stents. Reference stents control for probe placement and angulation, thus providing reproducible measuring sites. ${ }^{39}$ Badersten et al. ${ }^{40}$ and Clark et al. ${ }^{41}$ support the use of reference stents since they improve intraexaminer reliability and reproducibility of measurements compared to measurements taken from the cemento-enamel junction.

In this study, the position of the free gingival margin, attachment, and bone levels remained stable between 3 and 6 months. However, others have found positional changes of the periodontal tissues during this time period ${ }^{16,23,33}$ and up to 12 months. ${ }^{24}$ Therefore, in regards to determining the appropriate time for definitive margin placement, the authors recommend the following: 1) Clinicians should closely monitor the healing of the periodontium in order to assess the maturation and stability of these tissues, particularly the free gingival margin. It may be that when the amount of osseous resection is based on the anticipated prosthetic finish line and the original length of the biological width, the definitive margin could be constructed 3 months following surgical crown lengthening even in esthetic areas. 2) Before this can be recommended, however, further clinical trials are needed to confirm our results and observe the positional changes of the periodontium beyond 6 months.

In conclusion, during surgical crown lengthening, the bone level was lowered to allow for placement of the prosthetic margin and reestablishment of the biological width. The biological width, at treated sites, was reestablished to its original vertical dimension by 6 months. In addition, a consistent $3 \mathrm{~mm}$ gain of coronal tooth structure was observed at the 3-and 6-month examinations.

\section{ACKNOWLEDGMENT}

This project was supported by the Alexander Fellowship, Virginia Commonwealth University, Richmond, Virginia.

\section{REFERENCES}

1. Silness J. Periodontal conditions in patients treated with dental bridges. II. The influence of full and partial crowns on plaque accumulation, development of gingivitis and pocket formation. J Periodont Res 1970;5:219-224.

2. Bader JD, Rozier RG, McFall WT, Ramsey DL. Effect of crown margins on periodontal conditions in regularly attending patients. J Prosthet Dent 1991;65:75-79.

3. Bader JD, Rozier RG, McFall WT. The effect of crown receipt on measures of gingival status. J Dent Res 1991; 70:1386-1389. 
4. Newcomb G. The relationship between the location of subgingival crown margins and gingival inflammation. $J$ Periodontol 1974;45:151-154.

5. Silness J. Periodontal conditions in patients treated with dental bridges. III. The relationship between location of the crown margin and the periodontal condition. J Periodont Res 1970;5:225-229.

6. Orkin DA, Reddy J, Bradshaw D. The relationship of the position of crown margins to gingival health. $J$ Prosthet Dent 1987;57:421-424.

7. Renggli H, Regolati B. Gingival inflammation and plaque accumulation by well adapted supragingival and subgingival proximal restorations. Helv Odontol Acta 1972; 16:99-101.

8. Block PL. Restorative margins and periodontal health: A new look at an old perspective. J Prosthet Dent 1987; 57:683-689.

9. Maynard JG, Wilson RD. Physiologic dimensions of the periodontium significant to restorative dentists. J Periodontol 1979;50:170-174.

10. Nevins $M$, Skurow HM. The intracrevicular restorative margin, the biological width, and maintenance of the gingival margin. Int J Periodontics Restorative Dent 1984; 4(3):30-49.

11. Palomo F, Kopczyk RA. Rationale and methods for crown lengthening. J Am Dent Assoc 1978;96:257-260.

12. Lundergan W, Hughes WR. Crown lengthening: A surgical flap approach. Compend Continuing Educ Dent 1996; 17:833-844.

13. Rosenberg ES, Cho SC, Garber DA. Crown lengthening revisited. Compend Continuing Educ Dent 1999;20:527542.

14. Rosenberg ES, Garber DA, Evian C. Tooth lengthening procedures. Compend Continuing Educ Dent 1980;1:161172.

15. van der Velden $U$. Regeneration of the interdental soft tissues following denudation procedures. J Clin Periodontol 1982;9:455-459.

16. Carnevale G, Sterrantino SF, Di Febo G. Soft and hard tissue wound healing following tooth preparation to the alveolar crest. Int J Periodontics Restorative Dent 1983; 3(6):36-53.

17. Oakley E, Rhyu IC, Karatzas S, Gandini-Santiago L, Nevins M, Caton J. Formation of the biologic width following crown lengthening in nonhuman primates. Int J Periodontics Restorative Dent 1999;19:529-541.

18. Gargiulo A, Wentz F, Orban B. Dimensions and relations of the dentogingival junction in humans. J Periodontol 1961;32:261-267.

19. Fugazzotto P. Periodontal restorative interrelationships: The isolated restoration. J Am Dent Assoc 1985;110: 915-917.

20. Inger JS, Rose LF, Coslet JG. The "biological width," a concept in periodontics and restorative dentistry. Alpha Omegan 1997;70:62-65.

21. Wagenberg BD, Eskow RN, Langer B. Exposing adequate tooth structure for restorative dentistry. Int J Periodontics Restorative Dent 1989;9:322-331.

22. Smukler H, Chaibi M. Periodontal and dental considerations in clinical crown extension: A rational basis for treatment. Int J Periodontics Restorative Dent 1997;17:464-477.

23. Bragger U, Lauchenauer D, Lang NP. Surgical lengthening of the clinical crown. J Clin Periodontol 1992;19: 58-63.

24. Pontoriero R, Carnevale G. Surgical crown lengthening:
A 12-month clinical wound healing study. J Periodontol 2001;72:841-848.

25. Silness J, Löe H. Periodontal disease in pregnancy II. Correlation between oral hygiene and periodontal condition. Acta Odontol Scand 1964;24:747-759.

26. Löe H, Silness J. Periodontal disease in pregnancy I. Prevalence and severity. Acta Odontol Scand 1963; 21:533-551.

27. Ochsenbein C, Bohannan HM. The palatal approach to osseous resection: I. Rationale. J Periodontol 1963;34: 60-68.

28. Lindhe J, Nyman S. The effects of plaque control and surgical pocket elimination on the establishment and maintenance of periodontal health. A longitudinal study of periodontal therapy in cases of advanced disease. $J$ Clin Periodontol 1975;2:67-79.

29. Lindhe J, Nyman S. Alterations of the position of the marginal soft tissue following periodontal surgery. J Clin Periodontol 1980;7:525-530.

30. Caton J, Nyman S. Histometric evaluation of periodontal surgery. III. The effects on bone resection on the connective tissue attachment level. J Periodontol 1981;52: 405-409.

31. Pennel BM, King KO, Wilderman MN, Barron JM. Repair of the alveolar process following osseous surgery. J Periodontol 1967;38:426-431.

32. Donnenfeld OW, Hoag PM, Weissman DP. A clinical study on the effects of osteoplasty. J Periodontol 1970;41:131 141.

33. Wilderman MN, Pennel BM, King K, Barron JM. Histogenesis of repair following osseous resection. J Periodontol 1970;41:551-565.

34. Dragoo MK, Williams GB. Periodontal tissue reactions to restorative procedures. Int $J$ Periodontics Restorative Dent $1981 ; 1(1): 8-23$.

35. Dragoo MK, Williams GB. Periodontal tissue reactions to restorative procedures: Part II. Int J Periodontics Restorative Dent 1982;2(2):34-45.

36. Kalkwarf KL, Kaldahl WB, Patil KD. Comparison of manual and pressure-controlled periodontal probing. J Periodontol 1986;57:467-471.

37. van der Velden $U$, de Vries JH. The influence of probing force on the reproducibility of pocket depth measurements. J Clin Periodontol 1980;7:414-420.

38. Walsh TF, Saxby MS. Inter- and intra-examiner variability using standard and constant force periodontal probes. $J$ Clin Periodontol 1989;16:140-143.

39. Isidor F, Karring T, Attstrom R. Reproducibility of pocket depth and attachment level measurements when using a flexible splint. J Clin Periodontol 1984;11:662-668.

40. Badersten A, Nilveus R, Egelberg J. Reproducibility of probing attachment level measurements. J Clin Periodontol 1984;11:475-485.

41. Clark DC, Chin Quee T, Bergeron MJ, Chan ECS, LautarLemay C, de Gruchy K. Reliability of attachment level measurements using the cemento-enamel junction and a plastic stent. J Periodontol 1987;58:115-119.

Correspondence: Dr. Sharon K. Lanning, University of Michigan, School of Dentistry, Department of Periodontics/ Prevention/Geriatrics, 1011 N. University, Ann Arbor, MI 48109. E-mail: sklannin@umich.edu.

Accepted for publication August 30, 2002. 